\title{
La obra tardogótica de la Cartuja de la Defensión de Jerez de la Frontera. Reflexiones sobre la intervención de Diego de Riaño
}

\author{
The late gothic work of la Cartuja de la Defensión in \\ Jerez de la Frontera. \\ Reflections on the contribution of Diego de Riaño
}

\author{
Raúl ROMERO MEDINA \\ Universidad Internacional de La Rioja - UNIR
}

Manuel ROMERO BEJARANO

Universidad de Sevilla

Recibido: 1-IV-2017

Aceptado: 25-V-2017

RESUMEN: La Cartuja de la Defensión en Jerez de la Frontera es uno de los edificios tardogóticos mas importantes de la Baja Andalucía. Su construcción se lleva a cabo a la sombra de los arquitectos que trabajan para la Catedral de Sevilla, junto a otros maestros del ámbito local. En esta obra se ha podido documentar a Diego de Riaño, un arquitecto clave para poder entender la transición de los lenguajes arquitectónicos desde el último gótico a las primeras formas renacentistas. En este artículo se analiza la construcción de su obra y se reflexiona sobre la intervención del maestro Diego de Riaño.

Palabras claves: Tardogótico, Cartuja de la Defensión, Jerez de la Frontera, Arzobispado de Sevilla, Diego de Riaño.

ABSTRACT: La Cartuja of la Defensión in Jerez de la Frontera is one of the most important late-Gothic buildings in Lower Andalusia. The construction work was carried out under the supervision of the architects who were working for the Cathedral of Seville, along with other masters in the local area. The documents about the construction of La Cartuja de la Defensión show the importance of Diego de Riaño which is the key to understand the transition of architectural languages from the Late Gothic to the first Renaissance forms.

This article analyses the construction work and how important is the role that Diego de Riaño played in the work. Keywords: Late Gothic, Cartuja of la Defensión, Jerez de la Frontera, Archbishop of Seville, Diego de Riaño.

\section{EL ARQUITECTO DIEGO DE RIAÑO}

Las obras de la Cartuja de Nuestra Señora de la Defensión, en Jerez de la Frontera, son una respuesta a las novedades arquitectónicas que venían desde Sevilla, y que se difundieron por el amplio espacio territorial que comprendía su Arzobispado. La documentación demuestra que los maestros mayores responsables de la construcción de la Catedral Hispalense se vieron implicados en las obras parroquiales, monasterios y cartuja 
dependientes de su área de influencia, a la que pertenecía Jerez de la Frontera.

Así las cosas, solo cabe afirmar que la construcción de la Catedral de Sevilla supuso un imponente laboratorio de formas arquitectónicas que evolucionaron desde el Tardogótico al primer Renacimiento ${ }^{1}$. Desde 1434, este edificio vino a renovar la arquitectura de toda la Baja Andalucía, principalmente del área jerezano-portuense ${ }^{2}$, gracias a la presencia de maestros foráneos y a varias generaciones de maestros hispanos. Los intercambios artísticos y las conexiones familiares de los maestros canteros, protagonizaron en la zona de la Baja Andalucía uno de los fenómenos arquitectónicos de mayor calado que repercutiría en Canarias y América.

En la confluencia del lenguaje del ultimo gótico con las formas clásicas renacentistas se sitúa la figura del maestro Diego de

${ }^{1}$ Un análisis de los talleres de cantería en J. C. RODRÍGUEZ ESTÉVEZ, Los canteros de la Catedral de Sevilla. Del Gótico al Renacimiento, Sevilla, 1998. Un estudio más reciente que rebate ciertas hipótesis $\mathrm{y}$ que recoge toda la bibliografía surgida a posteriori de la publicación de ese libro en A. JIMÉNEZ MARTÍN, Anatomía de la Catedral de Sevilla, Sevilla, 2013.

${ }^{2}$ La influencia de la Catedral de Sevilla en el área jerezano-portuense hizo ya a Gestoso acuñar el término de gótico catedralicio para referirse a los edificios que se levantan a la sombra de su influencia. J. GESTOSO PÉREZ, Sevilla Monumental y Artística. Historia y Descripción de todos los Edificios Notables, Religiosos y Civiles, que existen actualmente en esta ciudad y noticias de las preciosidades artísticas y arqueológicas que en ello se conservan, T. II, Sevilla, 1890. Con posterioridad, este tema fue tratado desde una perspectiva muy general, no documental sino estilística, por J. C. RODRÍGUEZ ESTÉVEZ, “El Gótico Catedralicio. La Influencia de la Catedral en el Arzobispado de Sevilla", en Simposium Internacional Sobre la Catedral de Sevilla en el Contexto del Gótico Final, Sevilla, 2007, pp. 175-255. La lectura de dos recientes tesis doctorales analiza de forma pormenorizada este proceso a la luz de fuentes documentales que se encontraban inéditas. $R$. ROMERO MEDINA, Arquitectura medieval en El Puerto de Santa María. Del Islam a los inicios del Renacimiento, Tesis doctoral defendida en la Universidad de Cádiz, Cádiz, 2009. M. ROMERO BEJARANO, Maestros y obras de ascendencia portuguesa en el tardogótico de la Baja Andalucía, Tesis doctoral defendida en la Universidad de Sevilla, Sevilla, 2014.
Riaño, cuya influencia en la Baja Andalucía podría ser comparada a la que ejerció Diego de Siloé en la zona oriental andaluza o Alonso de Covarrubias en Castilla. Sus orígenes se sitúan en Riaño ${ }^{3}$, localidad del municipio de Solórzano, en la región montañesa de Trasmiera, desde donde las redes sociales de cantería le impulsaron a Castilla .

Sus inicios profesionales en Castilla se encuentran bastante desdibujados, pero todo apunta a que debió formarse en el foco de cantería de Burgos, junto a los maestros Juan del Castillo y Juan Gil de Hontañón, con los que tuvo una estrecha relación hasta el punto de que estos determinaron su trayectoria como maestro.

En este sentido, Diego de Riaño llegó a Sevilla con el taller de Juan Gil de Hontañón cuando en 1513 se le nombra maestro mayor de la Catedral Hispalense ${ }^{5}$. A pesar de que Camón Aznar sostuvo que cuando Riaño llegó a Sevilla era ya un maestro con fama adquirida en sus obras castellanas ${ }^{6}$, la documentación permite señalar que en estos momentos sólo era un oficial de taller que no disponía aún de reconocimiento en el oficio.

\footnotetext{
3 Resulta curioso cómo la historiografía clásica señala desconocer la procedencia del maestro. F. SOJO Y LOMBA, Los maestros canteros de Trasmiera, Madrid,1935. Sin embargo, el documento publicado por Hernández Díaz en el que un tal Pedro de Riaño se obligaba a pagar a Diego de Riaño la cantidad de cuarenta y dos ducados en concepto de préstamo, deja clara su procedencia. J. HERNÁNDEZ DÍAZ, Documentos para la Historia del Arte en Andalucía, Sevilla, 1933. p. 9. Para Morales Martínez Pedro de Riaño es el maestro que trabaja en la obra del Ayuntamiento de Sevilla sin más relación con Diego de Riaño que la de compatriotas, pues no se recoge en su relación de herederos. A. J. MORALES MARTÍNEZ, La obra renacentista del Ayuntamiento de Sevilla, Sevilla, 1981, p. 29. Por su parte, Camón Aznar los hace hermanos. J. CAMÓN AZNAR, La Arquitectura y la Orfebrería Española del siglo XVI, vol. XVII, Madrid, 1959 , p. 329.
}

${ }^{4}$ A. I. CAGIGAS ABERASTURI, Los maestros canteros de Trasmiera. Santander, Tesis Doctoral defendida en la Universidad de Cantabria, Santander, 2016.

5 T. FALCÓN MÁRQUEZ, La catedral de Sevilla. Estudio Arquitectónico, Sevilla, 1980, pp. 130-133.

${ }^{6}$ J. CAMÓN AZNAR, Op.cit.,p. 329. 
Con mayor precisión los datos documentales sitúan a Riaño en Sevilla, en 1517, como miembro del taller de su catedral bajo la dirección de Juan Gil de Hontañón ${ }^{7}$. Ese año hiere de muerte con un mazo a Gonzalo de Rozas, un compañero del taller, hermano de Aparicio de Ramales ${ }^{8}$. Estas circunstancias sobrevenidas le obligan a exiliarse a Lisboa, quizá ayudado de la mano de su compatriota Juan del Castillo, por entonces un maestro que gozaba de fama en el país luso. Juan del Castillo había trabajado en el taller catedralicio sevillano bajo las órdenes del maestro Alonso Rodríguez ${ }^{9}$, el antecesor de Juan Gil de Hontañón. Antes de su llegada a Sevilla, Juan del Castillo pudo coincidir con Diego de Riaño cuando se formaban como maestros, bajo el cobijo del taller de los Colonia, con el maestro Hontañón. Por tanto, los lazos de solidaridad entre Riaño y del Castillo eran tan estrechos que este último le dio asilo en Portugal.

Efectivamente, Riaño permanece en Portugal entre 1517 y 1522, año en el que recibe el perdón de Carlos $\mathrm{V}$ y regresa a Andalucía $^{10}$. No obstante, su presencia no se documenta en Sevilla hasta el 23 de junio de 1523, cuando otorga poder a Rodrigo de Simancas, vecino de Carmona, para que cobrase una deuda procedente de una cantidad entregada con el fin de prestar cierto servicio en Portugal que no se había ejecutado ${ }^{11}$.

Como afirma Alonso Ruiz, en 1523 Riaño era ya un maestro de reconocido presti-

${ }^{7}$ A. J. MORALES MARTÍNEZ, “Diego de Riaño en Lisboa", Archivo Español de Arte, 264, 1993, pp. 404-408.

${ }^{8}$ Ibídem.

${ }^{9}$ R. ROMEROMEDINAyM.ROMEROBEJARANO, “Un lugar llamado Jerez. El maestro Alonso Rodríguez y sus vínculos familiares y profesionales en el contexto de la arquitectura del tardogótico en Jerez de la Frontera", en La Catedral después de Carlín, Sevilla, 2010, pp. 173-288. J.C. RODRÍGUEZ ESTÉVEZ, “El maestro Alonso Rodríguez", en B. ALONSO RUIZ (ed.), Los últimos arquitectos del gótico, Madrid, 2010, pp. 271-360.

${ }^{10}$ A. J. MORALES MARTÍNEZ, “Diego de Riaño...”, pp. 404-408.

${ }^{11}$ J. HERNÁNDEZ DÍAZ, Op.cit., p.9. gio que estaba avalado por su dilatada experiencia en el taller sevillano ${ }^{12} \mathrm{y}$, añadimos además, su aprendizaje forzoso en las obras portuguesas. Ello hizo que Riaño fuese llamado a la junta de maestros para dar trazas de la colegiata de Valladolid, junto a Juan y Rodrigo Gil de Hontañón, Juan de Álava y Francisco de Colonia, antes de $1526^{13}$.

Riaño no fue llamado por casualidad a Valladolid, pues allí coincidió con los maestros implicados en las direcciones de las construcciones catedralicias en marcha. Por ello, cabe afirmar que desde el último trimestre de 1526 Diego de Riaño era ya responsable del taller catedralicio sevillano. A partir de esa fecha, la acumulación de cargos hace evidente que ya era un maestro de reconocido prestigio.

El 29 de marzo de 1527 aparece como maestro mayor en las nóminas de la obra del Cabildo Hispalense, si bien desde finales de 1526 ya debía de estar al frente de su construcción ${ }^{14}$. Por tanto, Diego de Riaño compaginó las maestrías mayores en Sevilla con la responsabilidad de la obra de la colegiata de Valladolid.

Los años que transcurren entre 1528 y el mes de enero de 1530 registran una actividad frenética del maestro, a juzgar por los pagos que recibe en concepto de honorarios y para sufragar el alquiler de las casas en las que vivía, en la Plaza de San Francisco, que eran propiedad de Constanza Hernández ${ }^{15}$. La implicación de Diego de Riaño en sus obras no sólo pasaba por la dirección, sino que ejecutaba a pie de obra y supervisaba la saca de la piedra de Martelilla, de las canteras de Jerez de la Frontera, ciudad a la que realizó varios desplazamientos para este menester ${ }^{16}$.

${ }^{12}$ B. ALONSO RUIZ, “Diego de Riaño y los maestros de la Colegiata de Valladolid", De Arte, 3, 2004, p. 40.

${ }^{13}$ Ibídem.

${ }^{14}$ A. J. MORALES MARTÍNEZ, La obra renacentista..., pp. 30-31.

${ }^{15}$ Ibídem.

${ }^{16}$ Archivo de Protocolos Notariales de Jerez de la Frontera (en adelante APNJ), Oficio IV. Juan Rodríguez, 
A principios de 1530 las obras del Cabildo sevillano se paralizaron y así debieron permanecer hasta $1532^{17}$. Es por ello por lo que el maestro aprovechó para realizar una larga visita en Valladolid, de cuyas obras era responsable, y aprovechar para dar informes como el de la iglesia de Santa María de la Antigua, en $1531^{18}$.

A partir de 1532 Diego de Riaño regresa a Sevilla al calor de las obras del Cabildo sevillano que se reanudaban. De hecho, en junio de ese año realiza una estancia en El Puerto de Santa María para supervisar la saca de piedras de las canteras de la Sierra de San Cristóbal $^{19}$. Gracias a estos contactos, el maestro se vio implicado en las obras de la Cartuja de la Defensión en la vecina ciudad de Jerez de la Frontera y consta que en 1533

fol. 196r. y siguientes. 16 de febrero de 1528. El cantero Juan Sánchez vende a Diego de Riaño 1000 sillares sevillanos y 200 tablas de las canteras de Martelilla, suponemos que para la obra de las Casas Capitulares de Sevilla. Resulta curioso que el precio de los sillares no era uniforme, ya que se dice en el documento que 170 de ellos valían un real de plata y el resto 40 maravedíes. Respecto a las tablas, éstas valían 48 maravedíes cada una. El cantero había recibido a cuenta del monto total en el momento del otorgamiento 7000 maravedíes, abonándosele el resto conforme fuese entregando la piedra. El plazo de entrega del material era el siguiente: 170 sillares y 30 tablas desde el día del otorgamiento hasta el 21 de febrero siguiente; el resto, desde el día del otorgamiento hasta el siguiente 15 de mayo, dando cada semana 100 piezas de cantería.

17 Alfredo Morales analiza pormenorizadamente estas circunstancias y narra las múltiples pérdidas que esta situación, cuyas causas no se conocen, generó en los maestros canteros empleados, especialmente, los sacadores quienes a pesar de haber trabajado a su costa les fueron embargadas las carretadas de piedra que tenían dispuestas para entregar. A. J. MORALES MARTÍNEZ, La obra renacentista..., pp. 32-33.

18 J. J. MARTÍN GONZÁLEZ y J. URREA FERNÁNDEZ, Catálogo Monumental de Valladolid. Monumentos religiosos de la ciudad de Valladolid (Catedral, parroquia, cofradías y santuarios), Valladolid, 1985, pp. 172-177.

${ }^{19}$ A. J. MORALES MARTÍNEZ, Laobra renacentista..., p. 34 . era maestro mayor de su fábrica e intervenía en las bóvedas de la nave de la iglesia ${ }^{20}$.

El maestro está perfectamente documentado en Sevilla en los meses de febrero, abril y mayo de 1533, así como entre marzo y mayo de $1534^{21}$. Entre julio y agosto de 1534 sus procuradores, los maestros Juan Picardo y Martín de Gaínza, recibían un poder para cobrar sus deudas. Ello implica que el maestro podía estar ausente de la ciudad, quizá en Valladolid o preparando su viaje a la capital castellana dónde le sorprendería la muerte en 1534, "el ultimo día del mes de noviembre deste dicho anno día de Santo Andres"22.

Como en su día sostuviera Alfredo Morales y remarcaría Begoña Alonso, Diego de Riaño tuvo varias desavenencias con el Cabildo catedralicio sevillano que nunca vio con buenos ojos sus estancias en Valladolid. Sin embargo, lejos de no tener exclusividad con la obra catedral hispalense y de que pusiera o no fin a las obras que tenía comenzadas en Valladolid, la ambición del maestro y su capacidad de trabajo no tenía límites. Así, por un poder que en 1533 da al mercader Juan de Escalante, sabemos que era maestro mayor en las iglesias de Arcos de la Frontera, de la Cartuja de Jerez de la Frontera, y de las iglesias de Carmona, Aracena, Aroche, Encinasola y Chipiona ${ }^{23}$.

La larga lista de obras a las que Riaño se vio vinculado denota a un maestro que por encima de su capacidad de trabajo demos-

${ }^{20}$ J. HERNÁNDEZ DÍAZ, Op. cit., p. 10.

${ }^{21}$ A. J. MORALES MARTÍNEZ, La obra renacentista..., p. 35.

${ }^{22}$ Ibídem, p. 37. Este autor dio a conocer el inventario de bienes post mortem del maestro, que se realizó el 17 de diciembre de 1534 en presencia de sus procuradores, Martín de Gaínza y Juan Picardo. En él se hace constar las cantidades que se le adeudaban por las obras de la Iglesia de Sevilla, el convento de San Francisco y las iglesias de Carmona, Arcos, Aracena, Aroche, Aznalcóllar y otras. La escasez de bienes es un elemento que resulta llamativo, junto a algunas herramientas y "ciertos papeles de debuxo de su oficio".

23 J. HERNÁNDEZ DÍAZ, Op. cit., p. 9. A. J. MORALES MARTÍNEZ, La obra renacentista..., p. 35. 
trada, debió contar con un nutrido equipo de colaboradores que ejecutaba sus trazas, lo que prueba que actuaba como un moderno contratista de obras. El maestro no dejaba pasar la oportunidad de coger la responsabilidad de una nueva fábrica o dar trazas. A veces, esos contactos eran casuales, como el que le debió vincular con la localidad de Morón de la Frontera o Utrera. A esta última ciudad debió desplazarse en varias ocasiones para igualar las carretas de piedra de sus canteras, en el donadío de la Torre del Águila, que eran propiedad de Sevilla ${ }^{24} \mathrm{y}$ fruto de ello fue su intervención en la iglesia de Santiago en dicha localidad. Sin embargo, nos interesa su implicación en la Cartuja jerezana a la que consagremos los siguientes apartados.

\section{DATOS SOBRE LA FUNDACIÓN DE LA CARTUJA DE LA DEFENSIÓN}

La Cartuja de Santa María de la Defensión fue fundada en Jerez de la Frontera en 1476 por el caballero jerezano Alvar Obertos de Valeto, quien donó su cuantiosa fortuna para la construcción del cenobio. Según el Protocolo Fundacional del monasterio, el noble Obertos, antes de morir en 1482, "vio hecha la capilla mayor de la iglesia hasta el entablamento y el capitulo de los monjes y sacristía en perfección" ${ }^{25}$. Sin embargo, el referido Protocolo también afirma que debido a un pleito suscitado por la herencia de Obertos de Valeto, tras su muerte las obras no se reanudaron hasta la década de los años veinte del XVI.

Por tanto, el manuscrito viene a señalar que desde 1482 hasta 1520 no se realizaron

\footnotetext{
${ }^{24}$ Tenemos constancia de que el maestro se desplaza a Utrera, al menos en dos ocasiones, en 1531, cuando el cabildo catedralicio estudiaba traer esa piedra para la construcción de la Sacristía Mayor, o en febrero de 1533, cuando se le paga 5000 maravedíes para un viaje a igualar las carretas de piedra. J.C. RODRÍGUEZ ESTÉVEZ, Los canteros de la catedral de Sevilla...;p. 359.

${ }^{25}$ J. MAYO ESCUDERO (ed.), Protocolo primitivo y de fundación de la Cartuja Santa María de la Defensión. Jerez de la Frontera (Cádiz), Salzburgo, 2001, pp. 24 y siguientes.
}

obras en el edificio. A pesar de ello, dentro del monasterio se localizan otros elementos que parecen haber sido construidos con anterioridad a 1520, pues son idénticos a algunos edificios góticos que se estaban levantando en Jerez de la Frontera, cuyos elementos denotan la inercia de la tradición de un estilo local antes de la llegada de influencias castellanas y portuguesas ${ }^{26}$.

Uno de los problemas con el que nos encontramos es poder determinar a qué maestros constructores se pueda deber la dirección y ejecución de las obras que se acometieron durante el siglo XVI. Algunos datos son conocidos por referencias indirectas, como reconocimientos de deuda, compras de cantería o subcontrataciones.

El sistema de funcionamiento de su fábrica, el organismo autónomo que regía la administración de la obra, era un tanto particular. Así, la relación laboral entre los operarios y los monjes cartujos se hacía por largos periodos de tiempo y de forma privada, debido a su vida de clausura, por lo que no se asentaban estos contratos en las notarías o escribanías públicas de la ciudad.

A pesar de ello, documentos indirectos como el testamento del carpintero Juan Rebollo, otorgado en 1546, nos confirman esta forma de proceder cuando afirmaba "que me deven los frayles del monasterio de la cartuxa estramuros desta çibdad del serviçio que monta el tiempo que a corrido desde el dia de año nuevo hasta la vispera de san Pedro que agora paso deste año a razon de nueve myll maravedis por año de los que alli servi en mi ofiçio de carpintero" ${ }^{27}$. Además, nos permite incluso conocer que los operarios realizaban otros trabajos a nivel particular para los frailes cuando el propio Rebollo confirma "que me debe Solochano monge en el dicho monesterio de cartuxa un duca-

26 R. ROMERO MEDINA y M. ROMERO BEJARANO, Op.cit.,pp. 173-288.

${ }^{27}$ APNJF, Oficio V. Rodrigo de Rus, fols. 690r. y siguientes. 24 de julio de 1546. 
do sobre un cruçifixo engastado en madera mando que se cobre del"28.

En función de las noticias que hemos podido localizar en la documentación histórica conservada y en las relaciones estilísticas que presenta esta fábrica con otras similares, pretendemos abordar la construcción tardogótica de esta obra con especial hincapié en la intervención del maestro Diego de Riaño y en el análisis de su figura.

\section{LA CONSTRUCCIÓN DE LA IGLESIA}

A la muerte de Alvar Obertos de Valeto las obras de la iglesia apenas si habían comenzado, ya que tan solo se habían levantado los muros de la capilla mayor hasta la altura del entablamento ${ }^{29}$. Se abre aquí un periodo oscuro en la historia del edificio, pues se desconoce cuándo se fabrica el resto de los muros perimetrales del templo, muy diferentes a los de la cabecera. Al exterior, los toscos pilares prismáticos rematados por una estructura triangular, han sido sustituidos por otros mucho más sofisticados (Fig. 1 ), que arrancan en un prisma de base rectangular pero que en la línea de imposta se bifurcan en un estribo de planta octogonal y un grueso pináculo recambiado y ricamente decorado con crochets, al modo de los que aparecen por las mismas fechas en las catedrales de Salamanca o Segovia. Ambas obras habían sido dirigidas por el reputado maestro Juan Gil de Hontañón (1470-1526). Las similitudes estilísticas permiten atribuir esta obra al maestro de Rasines, cuya impronta aparece en otros edificios de la ciudad ${ }^{30}$.

Juan Gil de Hontañón ejerció como maestro mayor de la Catedral de Sevilla,

\footnotetext{
${ }^{28}$ Ibídem.
}

${ }^{29}$ J. MAYO ESCUDERO, Op.cit., pp. 24 y siguientes.

30 R. ROMERO MEDINA y M. ROMERO BEJARANO, "Burgos, Jerez y Salamanca. Juan Gil de Hontañón y su obra en la parroquia de Jerez de la Frontera. Repercusiones en la catedral nueva de Salamanca", en M. CASAS HERNÁNDEZ (coord.), La catedral de Salamanca: de fortis a magna, Salamanca, 2014, pp. 2033-2046. M. ROMERO BEJARANO, Op.cit.

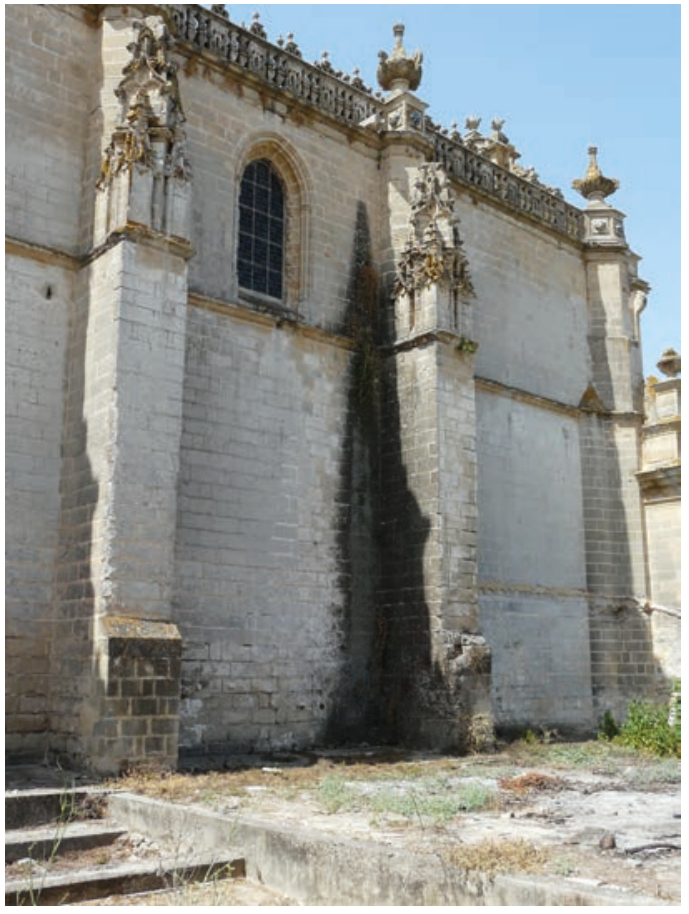

- Fig. 1. Cartuja de la Defensión, Jerez de la Frontera. Detalle de los pilares del muro de la iglesia. Foto de los autores.

tras la ruina del cimborrio, de manera intermitente, entre 1512 y 1518, y a él se deben las trazas del nuevo cerramiento del crucero. No era extraño que los maestros del primer templo hispalense diesen trazas para otros edificios del Arzobispado. Así las cosas, los maestros mayores de Sevilla solían dar trazas que luego supervisaban dejando las obras en manos de los maestros locales. Así, es posible que durante la segunda década del XVI, los cartujos, siempre ávidos de contratar a los mejores artistas para ennoblecer su casa, trajesen desde Sevilla a Juan Gil de Hontañón para continuar la obra de su iglesia, levantándose en este momento lo que faltaba de los muros perimetrales con sus estribos ricamente decorados. De hecho, durante la segunda década del XVI no cesó el suministro de materiales de construcción por parte del cenobio, por lo que es posible que una parte de los mismos se destinase a la ampliación de la iglesia ${ }^{31}$.

${ }^{31}$ APNJF, Oficio II. Sebastián Gaitán, fols. 211r. y siguientes. 11 de marzo de 1510. Antón Lorenzo el Viejo y su hijo Antón Lorenzo el Mozo venden a Bartolomé 
Hubo que esperar al priorato de Dom Andrés de Salas, que transcurrió entre 1525 y 1528, para que se cubriese la capilla mayor y se solase este trozo de la iglesia, lo que parece indicar que se preparó esta zona del templo para habilitarla para el culto, mientras que el resto seguía en construcción ${ }^{32}$. En 1525 los canteros Juan Sánchez, Juan Moreno y Gregorio Martín venden 570 carretadas de cantería $^{33}$, encontrándose entre los cortes demandados torales y prendientes, utilizados para realizar arcos y nervios, respectivamente con lo que queda claro que por aquel en-

Sánchez, como mayordomo de La Cartuja, 35000 tejas y 16500 ladrillos. El precio era de 390 maravedíes cada millar de labor, habiendo recibido los tejeros como adelanto del pago 3000 maravedíes. El resto se les abonaría conforme fuesen entregando el material. El plazo de entrega abarcaba desde el 1 de abril al 29 de septiembre siguientes. Oficio VII. Luis de Llanos, fols. 336r. y siguientes. 29 de abril de 1516. Bartolomé Vivas, hijo del calero Juan Vivas, se obliga con Francisco de Ribadeneira, como mayordomo de La Cartuja, de hacer los cuatro hornos para cocer cal desde el día del otorgamiento al siguiente 29 de septiembre. Se le pagaban 1000 maravedíes "por el trabajo de cortar la leña de cada un horno, otros 1000 por cojer la leña de cada un horno e traella a la boca de cada uno de los dichos hornos. Además, el monasterio había de proporcionar carretas y bueyes para traer la leña, toda la herramienta necesaria y costear una persona armador que arme los dichos cuatro hornos, abonándole a Vivas otros 3000 maravedíes por el trabajo de aparejar e cojer cada uno de los dichos hornos". Se estipula en el contrato que el pago de todo el dinero había de hacerse el 29 de septiembre siguiente.

\section{${ }^{32}$ J. MAYO ESCUDERO, Op.cit., pp. 84-85.}

${ }^{33}$ APNJF, Oficio III. Rodrigo de Cuenca, fols. 663v. y siguientes. 23 de noviembre de 1525. Los canteros venden piedra de las canteras de El Puerto de Santa María, localidad limítrofe con Jerez de la Frontera, a saber, 1600 sillares de los que cabían cinco en cada carretada a un precio de 10,5 maravedíes cada uno; 50 torales de los que cabían cinco en cada carretada a un precio de 25 maravedíes cada uno; 100 sillares de los que cabían cinco en cada carretada a un precio de 2,5 maravedíes cada uno (del precio se intuye que serían de peor calidad que los otros sillares); por último 1800 prendientes de los que cabían diez en cada carretada a un precio de dos reales la unidad. El plazo de entrega abarcaba desde el 1 de febrero al 31 de mayo de 1526 . Como adelanto del pago de la piedra habían recibido 10 ducados, abonándosele el resto conforme fuesen entregando la cantería. tonces se estaban cerrando las bóvedas. En el registro de esta carta, firma como testigo el albañil Andrés Núñez del Río, quien podría ser el responsable de dar las trazas y dirigir las obras.

Hasta el momento no documentado, Andrés Núñez del Río había trabajado como agente de la Fábrica de la Catedral de Sevilla en Jerez. Esta ciudad y El Puerto de Santa María eran las localidades en las que se encontraban las canteras de la Sierra de San Cristóbal y, propiamente en el término de la localidad jerezana, las de Martelilla. Las canteras eran propiedad del concejo y este adjudicaba licencias para la extracción de la piedra a los canteros sacadores, de ahí que la Catedral de Sevilla negociara directamente con estos maestros la saca y aprovisionamiento de piedra. Por ello, el agente era una suerte de figura que velaba por lo intereses económicos de la Catedral Hispalense comprando la piedra y resolviendo posibles $\operatorname{conflictos}^{34}$. Los contratos para la saca de piedra eran muy abundantes, especialmente de los diferentes cortes de cantería de la Sierra de San Cristóbal, que era una piedra calcarenita de naturaleza blanda, así como los de la piedra de Martelilla que era de naturaleza más dura y que se utilizaba sobre todo para labores decorativas ${ }^{35}$.

En este sentido, hay que señalar que en 1528 se ha podido localizar en el Archivo de Protocolos Notariales de Jerez un total de 10 contratos de compra de cantería de la Sierra de San Cristóbal para la obra de del primer templo Hispalense, especificándose en todos ellos que las piedras habían de ser "de buena peña fasta ser acabadas a vista e esamen de Andres Nuñes cantero vecino de esta dicha

${ }^{34}$ J.C. RODRÍGUEZ ESTÉVEZ, Cantera y Obra: las canteras de la Sierra de San Cristóbal y la Catedral de Sevilla, El Puerto de Santa María, 1998, pp. 56 y siguientes.

35 R. ROMERO MEDINA y R. ROMERO BEJARANO, "Las marcas de cantería del puente de Cartuja de Jerez de la Frontera: Análisis Gliptográfico", en Actes du XVIIe Colloque International de Glyptographie a Cracovie, Braine-le-Château, 2011, pp. 319-332. 
çibdad (de Jerez)"36. Consta que por aquel entonces se estaban levantando las Capillas de los Alabastros, por lo que se entiende que el material iría destinado a su construcción. Además, en 1533 recibía un pago de 1.250 maravedíes "por el trabajo que ha tenido en señalar las piedras en las canteras" ${ }^{\prime \prime}$, mientras se estaban iniciando los trabajos de la Sacristía Mayor del templo Hispalense. Un año más tarde se encargaba de llevar desde Sevilla a Jerez el dinero necesario para pagar 18.000 maravedíes a los canteros que suministraban piedra para la catedral ${ }^{38}$. A su vez,

${ }^{36}$ APNJF, Oficio X. Baltasar de Lueña, fol. 177v. y siguientes. 20 de febrero de 1528 . El cantero Juan Sánchez vende al canónigo Juan de Herrera, como mayordomo de la Fábrica de la Catedral de Sevilla, un total de 330 sillares (de 4,5 palmos de altura, 2,5 de anchura y 2 de fondo), 130 tablas (de 4,5 palmos de altura, 3,5 de anchura y 1,5 de fondo) y 40 tabletas (cúbicas de 3,5 palmos de lado), a un precio cada sillar de 40 maravedíes, cada tabla de 48 maravedíes y cada tableta de un real. El plazo de entrega comenzaba el día del otorgamiento, y el cantero se obligaba a entregar cada semana 40 piezas, recibiendo cada domingo el importe de lo que hubiese entregado. Ibídem, fol. 179v. y siguientes. 20 de febrero de 1528; fol. 181v. y siguientes. 20 de febrero de 1528; fol. 183v. y siguientes. 20 de febrero de 1528; fol. 548r. y siguientes. 24 de julio de 1528; fol. 550v. y siguientes. 24 de julio de 1528; fol. 552v. y siguientes. 24 de julio de 1528; fol. 554r. y siguientes. 24 de julio de 1528; fol. 555v. y siguientes. 24 de julio de 1528; fol. 557r. y siguientes. 24 de julio de 1528.

${ }^{37}$ Archivo de la Catedral de Sevilla (en adelante ACS), Fondo Capitular. Fábrica. Libro del cargo e descargo de la mayordomía de la Fábrica de que fue mayordomo el señor canónigo Peñalosa. 1533, fol. 5r.

38 "Los quinze myll de ellos a Alonso de Hariza y Juan Sanchez y Anton Martyn y Hernan Rodrigues canteros veçinos de Xerez para en quenta de los sesenta y ocho myll y quinientos çinquenta maravedis que an de aver por myll y ochoçientos syllares y trezientas tablas que estan obligados a sacar de las canteras del puerto y con estos an reçibido çinquenta y dos myll e qunientos maravedis y los tres myll maravedis restantes para dar a Juan Garçia Pinçon carretero veçino del Puerto para en quenta de los veynte e un myll maravedis que a de aver por las seteçientos e çinquenta carretadas de piedra que esta obligado de traer de las canteras del puerto al muelle y con estos avia reçibido myll e quinientos maravedis". Ibídem, 1534, fol. 8r. y siguientes. Andrés Núñez recibió además 816 maravedíes por los seis días que se ocupó en venir por el dinero a Sevilla y llevarlo a Jerez. en 1538 y 1539, intervino en asuntos relacionados con el transporte de la piedra de las canteras de Martelilla que se había comprado para la obra de la Magna Hispalensis ${ }^{39}$, a buen seguro también para la Sacristía Mayor. Además de ser contratado en 1543 para realizar un tramo de bóveda en la jerezana parroquia de San Mateo, obra que al final no hizo ${ }^{40}$, consta que Núñez del Río intervino entre 1538 y 1544 en las obras de la desapa-

${ }^{39}$ APNJF, Oficio I. Francisco Román de Trujillo, fol. 73r. y siguientes. 10 de noviembre de 1538. Diego de la Peñuela, notario de la Santa Iglesia de Sevilla y en nombre de Juan de Moguer, como su mayordomo, pone de manifiesto que se había concertado con los carreteros Juan de la Fuente y Alonso Adán para que trajesen 600 carretadas de piedra, a un precio de 40 maravedíes cada carretada, desde las canteras de Martelilla hasta el arroyo del Amarguillo, junto al Guadalete, a un paraje denominado en el documento como "la legua del agua". Los citados carreteros no habían cumplido con su obligación, así que ahora firmaba un nuevo contrato con el carretero Juan Martín de Coria, para que trajese las 210 carretadas que los otros habían dejado de transportar, a un precio de 65 maravedíes la carretada. En el momento del otorgamiento se le abonaban 4550 maravedíes, otro tanto se haría cuando hubiese entregado 60 carretadas, y el último pago, de la misma cantidad, se haría cuando hubiese entregado otras 60 . Respecto al plazo de entrega, éste comenzaba el 12 de noviembre, "e no dexar de traer las dichas piedras no enbargando el tyenpo de lluvias e poder endar las carretas para echar la piedra". En el documento, firma como testigo Andrés Núñez del Río, lo que indica su relación con la Fábrica de la catedral de Sevilla, como se comprueba en otros documentos.

Ibídem, fol. 110r. 28 de mayo de 1539. Andrés Núñez del Río, quien actúa en nombre de la Fábrica de la Catedral de Sevilla, se concierta con los carreteros Alonso López Chamorro, Francisco García y Francisco Rodríguez para que trajesen 400 carretadas de piedra desde la cantera de Martelilla hasta el embarcadero del río Amarguillo. El plazo de entrega se dividía en dos partes. Desde el 2 de junio al 6 de julio siguientes habían de transportar 300 carretadas, mientras que el resto las tenían que llevar desde el citado 6 de julio hasta el 31 de agosto siguiente. El precio de traída de cada carretada era de 60 maravedíes que se habían de pagar en tres tercios: el primero en el momento de la firma del contrato, el segundo una vez traída la mitad de la piedra, y el tercero acabada de traer toda.

${ }^{40} \mathrm{M}$. ROMERO BEJARANO, Op.cit. 


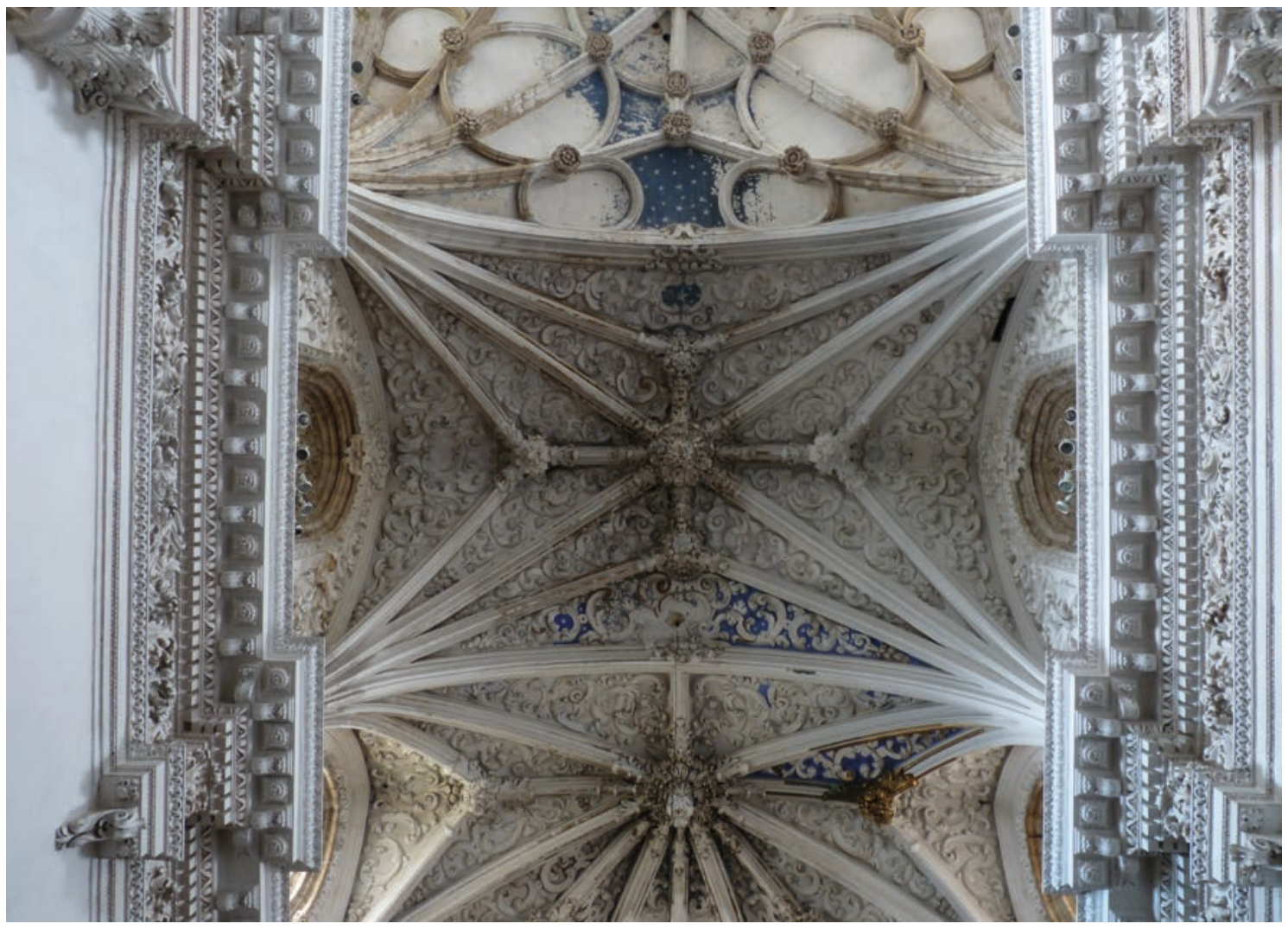

- Fig. 2. Cartuja de la Defensión, Jerez de la Frontera. Bóvedas de la capilla mayor de la iglesia. Foto de los autores.

recida iglesia de San Ildefonso, ubicada no muy lejos de San Mateo ${ }^{41}$.

De estos datos se deduce que Núñez del Río era un cantero jerezano buen conocedor del oficio, pero parece que su actividad estaba más centrada en la extracción y el suministro de piedra, ámbito que conocía a la perfección hasta el punto de ser una suerte de agente de la catedral de Sevilla en Jerez, que en el de la arquitectura. Así las cosas, lo que se conserva en la iglesia de San Mateo está firmado por Fernando Álvarez ${ }^{42}$, por lo que no hay certeza de que ninguna obra suya construida siga en pie. Aún así, hay que re-

41 Sobre este desaparecido templo, véase M. A. ÁlVAREZ LUNA, F. AROCA VICENTI, J. M. GUERRERO VEGA y M. ROMERO BEJARANO, “La iglesia de San Ildefonso", en J. JIMÉNEZ LÓPEZ DE EGUILETA (ed.), La Parroquia de San Mateo de Jerez de la Frontera. Historia, arte y arquitectura, Murcia, 2017 (en prensa).

${ }^{42}$ M. ROMERO BEJARANO, Op.cit. trotraerse a la década de los veinte del XVI, cuando los avances estéticos estaban llegando desde Sevilla, mientras que en Jerez aún pervivía la tradición local.

Su condición de maestro local, anquilosado en las técnicas constructivas de la segunda mitad del XV, hace pensar que Andrés Núñez del Río se encargó de dar las trazas y dirigir las obras que se estaban realizando en el monasterio hacia 1525, una vez que Juan Gil de Hontañón había abandonado de manera definitiva las tierras sevillanas. Ello nos permite atribuirle las trazas de las bóvedas de la capilla mayor del templo, ya que se trata de una cabecera pentagonal más dos tramos rectangulares (Fig. 2) todos cubiertos con bóveda de crucería con terceletes, solución muy común en la zona en ese periodo, como lo demuestran las numerosas capillas funerarias que se levantaron en los templos jerezanos en aquella época y la nave principal de la parroquia de Santiago, cuyas 


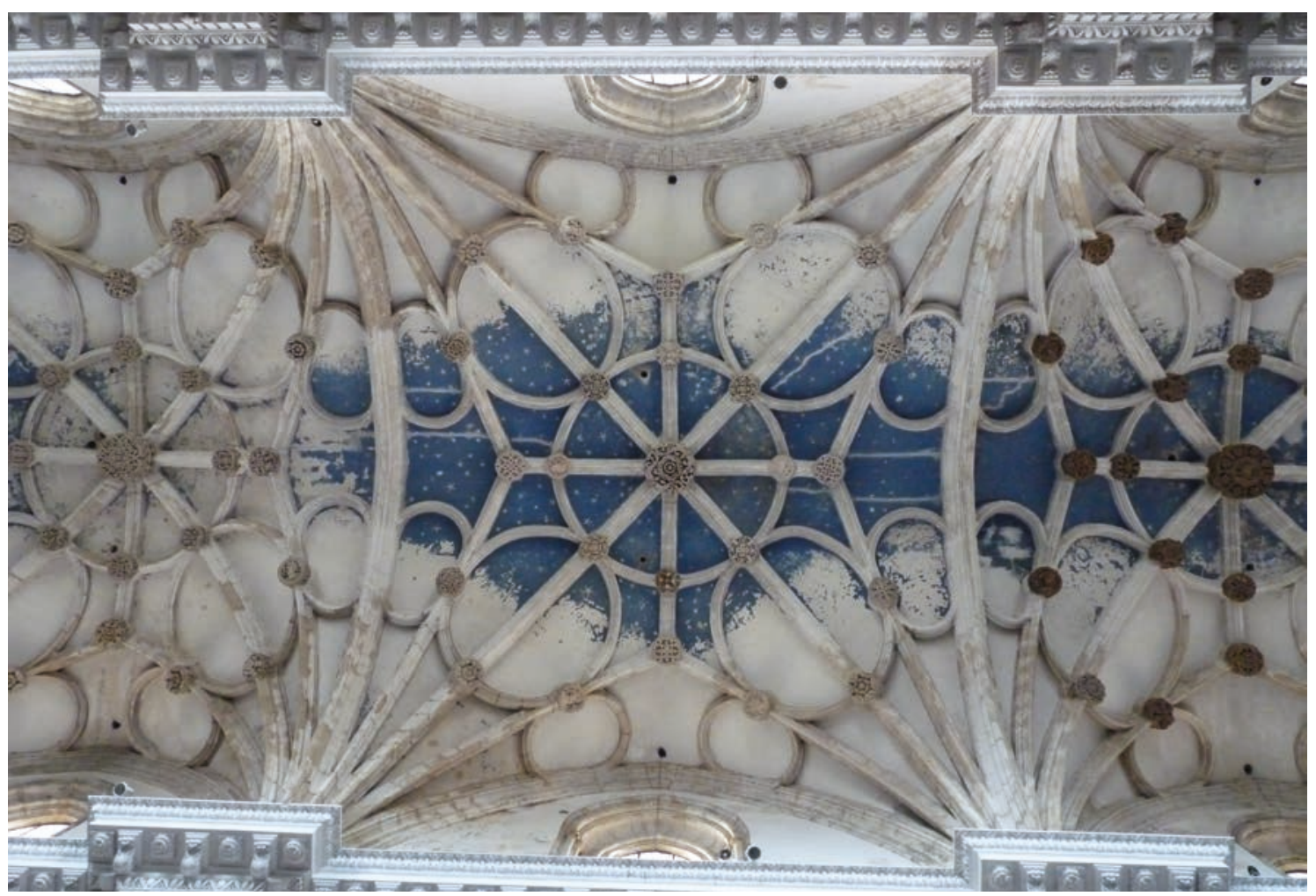

- Fig. 3. Cartuja de la Defensión, Jerez de la Frontera. Tramos de bóvedas de los pies de la iglesia. Foto de los autores.

obras se iniciaron en torno a $1496^{43}$. Las ventanas ubicadas en los muros de este sector resultan muy sencillas y con tracerías similares a otras contemporáneas, como las de la cabecera de la jerezana iglesia de San Mateo.

En 1529 fue elegido prior Dom Bruno de Hariza, quien en 1531 "tomo a pecho la obra de la iglesia en la cual su antecesor había cubierto la capilla mayor y diole tanta prisa que el dia de San Bernardo, que cae en 25 dias del mes de agosto año de 1534 años la acabó de cubrir que parece cosa imposible tan grande y de tallador en tan breve tiempo acabarle" ${ }^{\prime 4}$. De hecho, es asombroso que la obra se hiciese en tan corto espacio de tiempo, pues aún faltaban tres grandes campos de bóveda para acabar de cubrir por completo el templo.

43 R. ROMERO MEDINA y M. ROMERO BEJARANO, "Un lugar llamado Jerez...", pp. 256 y siguientes.

${ }^{44} \mathrm{~J}$. MAYO ESCUDERO, Op.cit., pp. 85 y siguientes.
Así las cosas, durante el priorato de Hariza tenemos constancia de la compra de importantes partidas de materiales por parte del monasterio, tales como cantería ${ }^{45}$, $\mathrm{cal}^{46} \mathrm{y}$ ladrillos ${ }^{47}$. Incluso hay un contrato de

45 APNJF, Oficio V. Antón García del Pecho, Foliación perdida. 16 de junio de 1531. Los canteros Diego Sánchez Melgar y Andrés García Manzanillo venden a la cartuja 1000 sillares de las canteras de El Puerto de Santa María, de los que cabían cinco en carretada, a precio de 11 maravedíes cada sillar. El plazo de entrega comenzaba al día siguiente del otorgamiento, entregando cada semana 60 sillares. Ya habían recibido la paga completa de todo el material.

${ }^{46}$ Ibídem. 8 de marzo de 1531. El calero Alonso Gil de Baeza se obliga a entregar a la cartuja 100 cahices de cal, a un precio de 90 maravedíes cada cahiz. El plazo de entrega era durante todo el mes de marzo. Como adelanto del pago había recibido 5000 maravedíes, entregándosele el resto conforme fuse suministrando la cal.

${ }^{47}$ Ibídem. 30 de mayo de 1531. Bruno de Hariza, como prior de la cartuja, da a hacer a destajo al tejero Alonso Gil Lorenzo y a su madre Antona Sánchez, "un tejar con dos hornos que el dicho monesterio tiene en los tejares para que este año en que estamos fagays vos 
1532 en el que los canteros Gregorio Martín, Francisco de Ledesma, Hernán Gómez y Bartolomé Gil se obligan a vender todos los sillaretes de las canteras de El Puerto de Santa María que necesitase el monasterio desde septiembre de ese año hasta junio de 1533, entregando cada día 30 piezas, especificándose que además de estos sillaretes habían

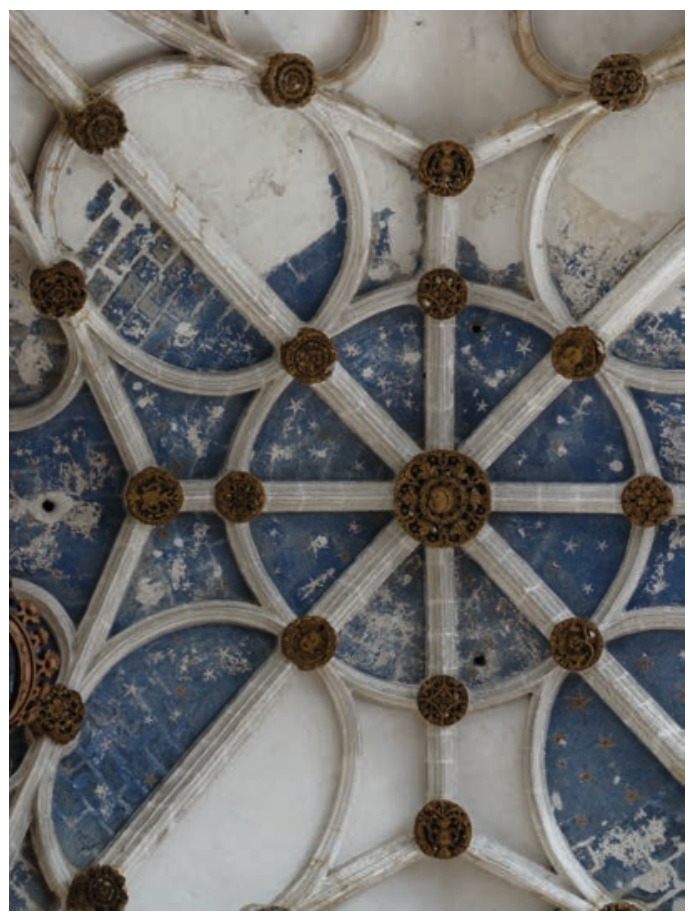

- Fig. 4. Cartuja de la Defensión, Jerez de la Frontera. Detalle de los plementos de la bóveda en hiladas redondas. Foto de los autores.

de dar "toda la canteria que de la dicha cantera hizieremos en este dicho tienpo ansy de sillaretes como prendientes como cantillos, comprometiéndose los canteros a no vender ny venderemos ny daremos nynguna de la dicha canteria a nynguna yglesia ny monesterio ny persona particular. Con esta suerte de actuaciones, la Cartuja quería asegurarse a toda costa un suministro masivo de piedra. Además, en el contrato se especifica que los

los suso dichos e deys fechos para el dicho monesterio quarenta e tres myllares de ladrillos". El precio total de la labor era de 45 ducados, que fueron abonados íntegramente a los tejeros en ese momento. Tenían que entregar 21500 ladrillos el siguiente 15 de julio y otros tantos el siguiente 15 de septiembre. sillaretes habían de ser buenos e de buena peña segun lo acostunbramos a dar al dicho monesterio" ${ }^{\prime 4}$, lo que hace pensar que eran proveedores habituales de piedra a los cartujos. La generalidad de los contratos en lo referente al tipo de cortes de piedra, permite establecer de manera clara qué elementos se estaban construyendo en ese momento, ya que los sillaretes se usaban para levantar muros y los prendientes para hacer nervios, con lo que queda claro que se estaban cerrando las bóvedas. Con todo, hay que tener en cuenta que ya por aquel entonces estaba en marcha la obra del Claustro Grande, que demandaba una cantidad ingente de material.

De los documentos se deduce que la obra en realidad no conoció interrupción. De hecho, la capilla mayor había terminado de cerrarse hacia 1529 y el resto comenzó a hacerlo en 1531, si bien los tres tramos de los pies del templo son muy distintos a los de la cabecera. Se trata de tres tramos idénticos de bóveda (Fig. 3) de crucería con terceletes, pero aquí abundan los combados. Hay un nervio circular en el rampante, del punto en que este nervio circular se une al principal nace otro nervio elíptico que alcanza el tercio central del nervio principal, y del punto en que esta elipse se une al tercelete inmediato, nace otro elíptico que llega a tocar el muro de la iglesia. Además, en los puntos en que el enlucido del plemento se ha perdido (Fig. 4), se puede ver que las hiladas están colocadas de manera concéntrica.

En este sentido, Pinto Puerto ${ }^{49}$, que ha estudiado con detenimiento la geometría de

${ }^{48}$ Ibídem, fol. 196v. y siguientes. 9 de septiembre de 1532. En nombre del monasterio actúa el prior, Dom Bruno de Hariza. El precio de los sillaretes era de 11 maravedíes la unidad, habiendo cobrado en el momento de la firma del contrato el importe total de la cantería. Durante el periodo estipulado Gregorio Martín y Bartolomé Gil habían de entregar 10 sillaretes cada uno al día, mientras que Francisco de Ledesma y Hernán Gómez habían de dar tan sólo cinco sillaretes cada uno. El precio al que se venderían los prendientes y los cantillos era de 2 reales cada carretada.

${ }^{49}$ F. PINTO PUERTO, Las esferas pétreas. Análisis de las soluciones del arte de la montea en la provincia de 


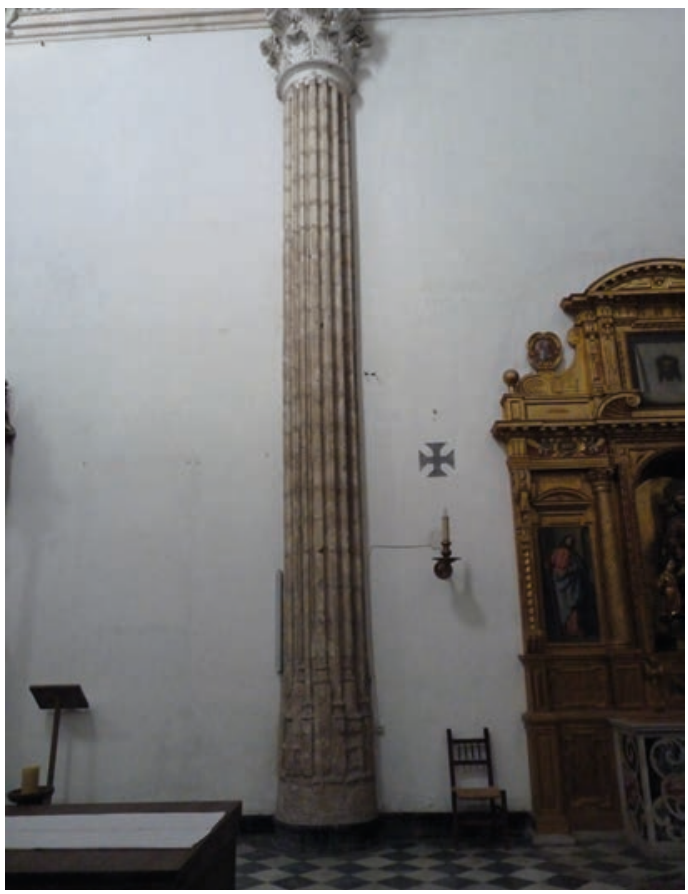

- Fig. 5. Cartuja de la Defensión, Jerez de la Frontera. Detalle del pilar adosado al muro de la iglesia. Foto de los autores.

estas bóvedas, nos dice, y cito textualmente, que se aproximan a la esfera hasta lo posible, ya que, al existir una fase previa de un gótico aún muy clásico, la intervención posterior tiene que mantener la forma apuntada de los arcos formeros. Las nuevas bóvedas están obligadas a realizar una transición entre estas hiladas esféricas y las formas apuntadas de estos arcos. El cambio de una a otra superficie se realiza con los terceletes, quedando toda la bóveda encerrada por ellos como una esfera. Los jarjamentos, remarcados visualmente por los nervios combados, aparentan ser conos curvilíneos, desde los que arrancan las citadas hiladas redondas. Es, junto al cierre de los presbiterios de las parroquias de San Marcos y San Mateo, de esta misma ciudad, los únicos ejemplos donde encontramos esta montea aplicada a la plementería.

En el arco de acceso de la capilla mayor, podemos ver adosados al muro dos pilares (Fig. 5) de planta circular de un aspecto casi

Cádiz durante el siglo XVI, Tesis doctoral defendida en la Universidad de Sevilla, Sevilla, 1998. columnario, por la disposición en que recogen los baquetones. En la mayor parte de las claves encontramos motivos decorativos de inspiración vegetal o geométrica, si bien en dos claves secundarias del tercer tramo hallamos dos cabezas grotescas, en la clave central del cuarto tramo el busto de Cristo y en algunas de las secundarias la cabeza de personajes barbados con extraños sombreros y en la clave central del último tramo algo que parece la cabeza de una dama tocada con un gorro, presentando dos de las claves secundarias de este tramo querubines.

En poco tiempo la iglesia de la Cartuja de Jerez sufrió un cambio radical, una castellanización, o si tenemos en cuenta el factor portugués, una internacionalización. Ahí están los combados, el plemento en hiladas redondas, los estribos ricamente decorados y los pilares de planta circular que dan paso a la capilla mayor para demostrarlo. La respuesta a este cambio estilístico sólo podría explicarse por un nuevo maestro mayor al frente de la obra, como así lo demuestra la documentación.

Así las cosas, por un documento de 1533 sabemos que Diego de Riaño da poder al mercader Juan Escalante "para que pueda pedir... de los mayordomos de las yglesias de la çibdad de arcos e de la cartuxa de la çibdad de Xeres de la Frontera e de las yglesias de Carmona e Aracena e Aroche e Encinasola y Chipiona... todos los maravedis que me deven... de mi salario de las dichas yglesias e de cada una de ellas como maestro mayor que soy de ellas" ${ }^{50}$. No se sabe con exactitud desde cuándo era Riaño maestro mayor de la Cartuja, pero sí que ya lo era en 1533, con lo que su presencia está documentada en plena ejecución de las bóvedas de la iglesia. Las innovaciones constructivas y ornamentales que encontramos en las mismas, hacen pensar que el maestro trasmerano se encargó de sus trazas.

Así pues, al llamar para la obra a Diego de Riaño, por aquel entonces maestro mayor

\footnotetext{
${ }^{50}$ J. HERNÁNDEZ DÍAZ. Op. cit., p. 9.
} 
de la Catedral de Sevilla, de nuevo encontramos en los padres cartujos ese afán de novedad y suntuosidad que a partir de esos momentos se convirtió en el sello de la casa. De hecho, ya por aquel entonces estaban en marcha obras como el Ayuntamiento de Sevilla o la Sacristía Mayor de la Catedral, en las que demostró su valía como uno de los mejores arquitectos españoles del momento.

Los trabajos en el templo quedaron concluidos con la fabricación de sus vidrieras a partir de 1535 por el burgalés Arnao de Vergara $^{51}$ y el flamenco Guillermo de Escora ${ }^{52}$, quienes realizaron un total de seis piezas de vivos colores en las que se representaba la Santa Cena, la Crucifixión, el Descendimiento, la Resurrección, la Ascensión y Pentecostés.

\section{LA CONSTRUCCIÓN DEL CLAUS- TRILLO}

La obra del Claustrillo de Santa María de la Defensión comenzó durante el priorato de Dom Andrés de Salas, entre 1525 y 1529, quien "comenzó a hacer el claustro chico y cubrió el de las capillejas del rincón" ${ }^{53}$. Las obras concluyeron durante el priorato de Bruno de Hariza, quien accedió al cargo en 1529 y en su gobierno "lo primero fue acabar el claustro chico y en espacio de dos años lo acabó con las dos capillas que en él están, que la una es el capítulo de los frailes y la otra es el tránsito de ellos para la iglesia" ${ }^{\prime 54}$. A tenor de lo que dice el Protocolo Fundacional del monasterio, en 1531 estaba concluida la obra. La importante compra de ladrillo y

\footnotetext{
${ }^{51}$ M. ROMERO BEJARANO, “El maestro Arnao de Vergara, autor de las primitivas vidrieras de la iglesia de la cartuja de Santa María de la Defensión de Jerez de la Frontera", en I. COLOMA MARTÍN, y J.A. SÁNCHEZ LÓPEZ (eds.), Actas del XIV Congreso Nacional de Historia del Arte, T. II, Málaga, 2003, pp. 451-458.
}

52 J. A. MINGORANCE RUIZ, "La presencia flamenca en la Cartuja de Santa María de la Defensión de Jerez de la Frontera", Atrio,18, 2002, pp. 137-150.

${ }^{53}$ J. MAYO ESCUDERO, Op.cit., pp. 84 y siguientes.

${ }^{54}$ Ibídem. teja efectuada en 1530 bien pudo destinarse a estos trabajos ${ }^{55}$.

La historiografía afirma que Diego de Riaño es el autor de las trazas de este claustro $^{56}$, algo que parece posible si se tiene en cuenta el documento de 1533 que citábamos al tratar de la iglesia, por el que Riaño apoderaba a Juan de Escalante para que cobrase de la Cartuja de Jerez lo que se le adeudaba como parte de su salario de maestro mayor del cenobio. Con todo, esta afirmación merece una matización que haremos más adelante.

El claustro (Fig. 6) se resuelve mediante cuatro galerías de bóvedas de crucería simple cuyos enjarjes en el muro se realizan adoptando una forma cilíndrica nervada de aspecto columnario (Fig. 7). Cada panda del claustro se abre al centro mediante cuatro arcos apuntados separados por estribos prismáticos con la base redondeada y coronados por pináculos ricamente decorados con crochets y gárgolas. Estos estribos han sido sustituidos en las esquinas (Fig. 8) por columnas de mármol blanco con capiteles de pencas y basas con garras, del modelo que tan frecuente se hizo en Jerez a partir de ese momento de la década de los veinte del XVI. Para salvar la diferencia de altura entre el capitel y el inicio del arco, se ha incluido un cimacio de cantería, pero este cimacio no presenta forma prismática, sino semiesferoide $\mathrm{y}$, a diferencia de los casos en la arquitectura civil jerezana de la década de los treinta del XVI, los bestiarios han sido sustituidos por

${ }_{55}$ APNJF, Oficio V. Antón García del Pecho, fol. 201r. y siguientes. 31 de marzo de 1530. Bruno de Hariza, como prior de la cartuja, da a destajo a Juan García de Tarifa "un tejar con dos hornos en el que dicho monasterio tiene en los tejares para que en este año hagays al dicho monesterio en el dicho tejar noventa e dos myllares de labor ochenta e quatro myll ladrillos e ocho myll tejas". El precio total de la obra era de 92 ducados, que el tejero ya había cobrado. El plazo de entrega de la obra abarcaba desde el 24 de junio al 31 de agosto siguientes.

${ }^{56}$ CARTUJO DE LA DEFENSIÓN, "El Claustrillo de la Cartuja de la Defensión", Temas de Estética y Arte, IX, 1995, pp. 173-200. 


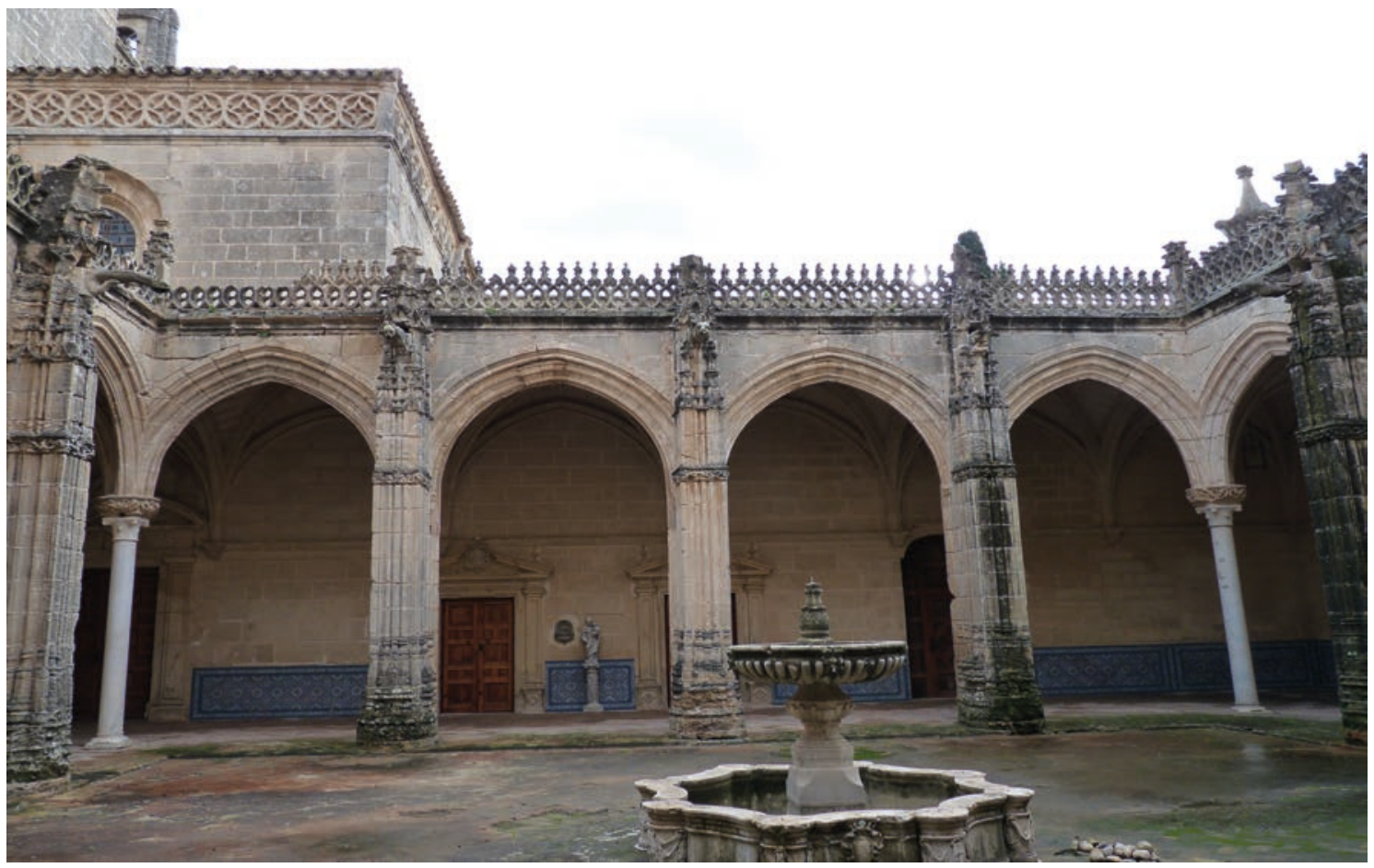

- Fig. 6. Cartuja de la Defensión, Jerez de la Frontera. Vista del claustrillo. Foto de los autores.

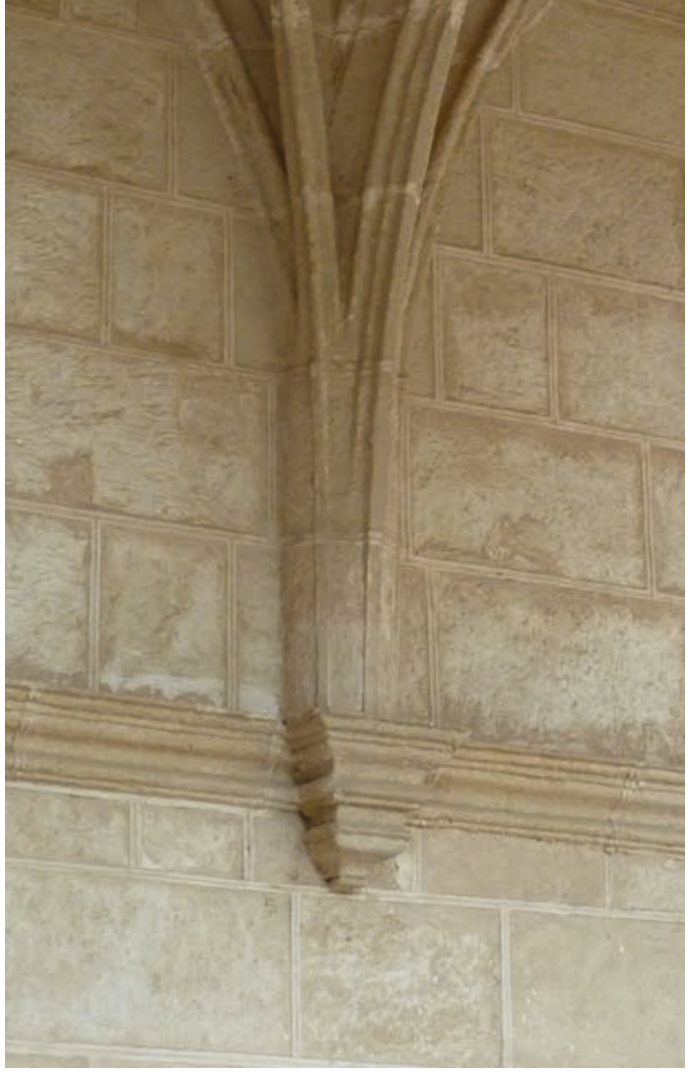

- Fig. 7. Cartuja de la Defensión, Jerez de la Frontera. Detalle de enjarje de bóveda en el claustrillo. Foto de los autores.

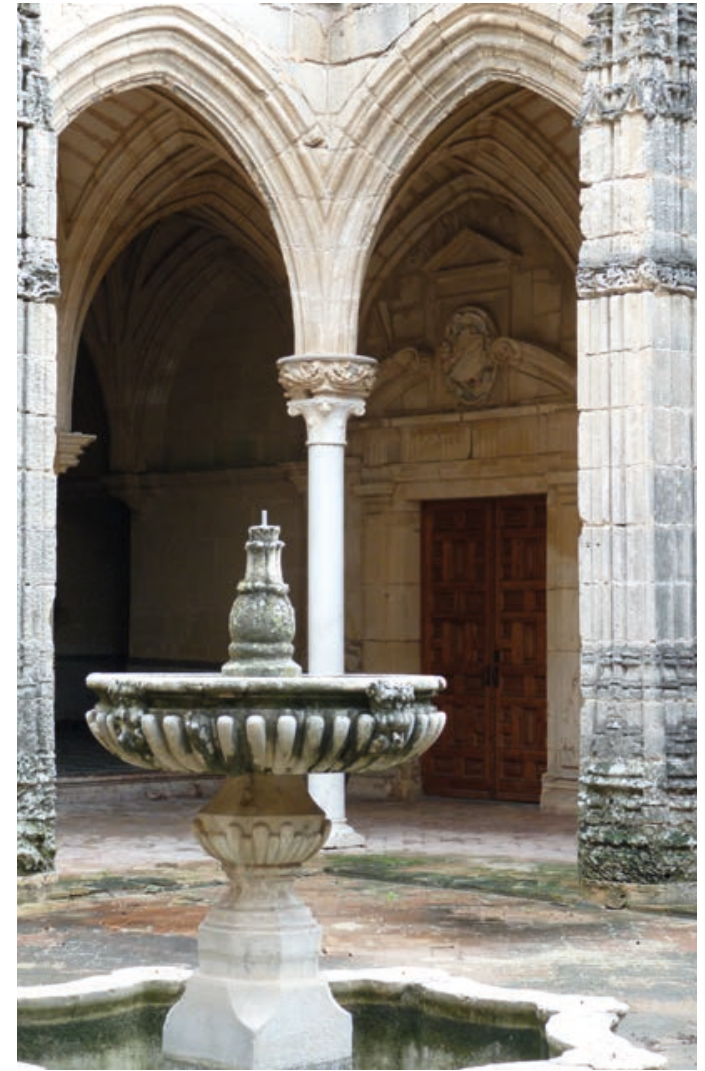

- Fig. 8. Cartuja de la Defensión, Jerez de la Frontera. Columnas de mármol del claustrillo. Foto de los autores. 
finos motivos ornamentales que representan animales fantásticos y roleos bien labrados al gusto "antiguo", es decir, renacentista. El conjunto se remata por una crestería. Lamentablemente, las ménsulas que reciben las nervaduras en el muro fueron ocultadas a mediados del siglo XVIII hasta el punto que hoy es irreconocible todo vestigio de la obra original ${ }^{57}$.

Parece extraño que mientras entre 1525 y 1529 se estaba levantando la capilla mayor en un estilo gótico totalmente anquilosado en la tradición, a unos pasos se hiciese un claustro con una clara voluntad de renovación artística. Máxime teniendo en cuenta el cambio experimentado por las bóvedas de la iglesia poco más tarde. Además, resultaría complicada una dirección de obras simultánea entre Andrés Núñez del Río y Diego de Riaño.

A pesar de ello, el Protocolo Fundacional de la Cartuja es claro al señalar que du- rante el priorato de Dom Andrés Salas se levantaron las bóvedas de las cuatro esquinas del claustro chico. No obstante, si se leen con detenimiento las obras realizadas durante el priorato de Bruno de Hariza, momento en que se concluye el Claustrillo, se dice que "él mandó traer la pila y la fuente y los cuatro mármoles que en el claustro chico están de Génova que costaron 80 ducados" ${ }^{\prime 58}$. Por tanto, hubo un cambio en el proyecto original, pues si una vez que ya estaban construidas las bóvedas de las cuatro esquinas, se trajeron las columnas de mármol que las sostienen en la actualidad, quiere decir que en un principio en esas esquinas habría otro elemento sustentante, posiblemente un estribo, que fue sustituido con el priorato de Dom Bruno de Hariza. Podría decirse que la elección de Riaño, quien no parece que se encontrase al frente de las obras antes de 1529, fue un experimento con vocación de modernidad por parte de unos monjes que acabaron tan satisfechos que le encargaron la continuación de

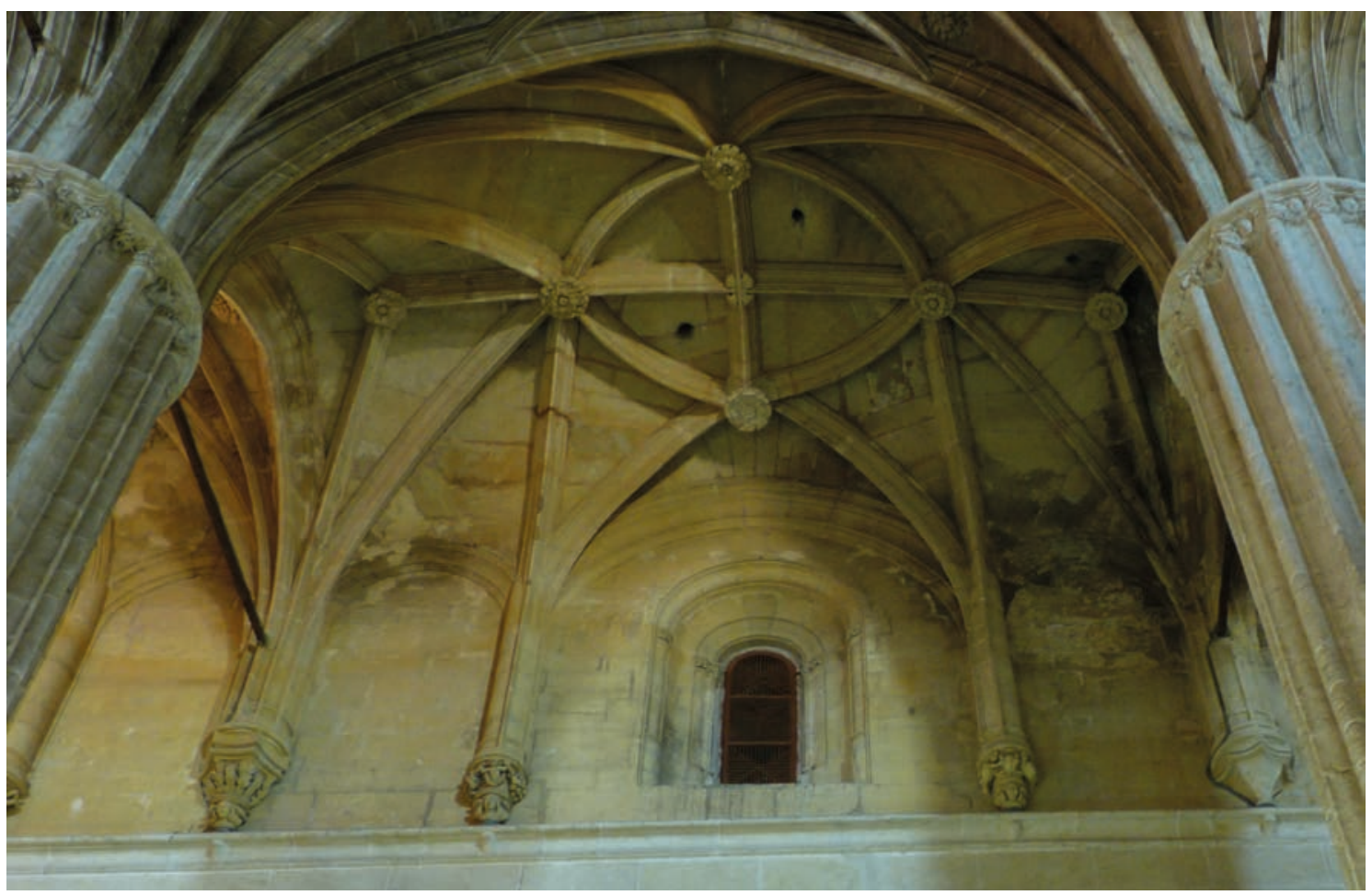

- Fig. 9. Iglesia de Santa María, Arcos de la Frontera. Detalle del enjarje de los nervios de la bóveda en el muro. Foto de los autores.

${ }^{57}$ Ibídem, p. 186.

${ }^{58} \mathrm{~J}$. MAYO ESCUDERO, Op.cit., p. 87. 
la iglesia en un estilo más acorde con lo que se estaba haciendo en otros centros de producción artística en ese momento. Una vez más, aparece la huella del tardogótico portugués en una obra dirigida por Riaño. Se ha señalado que los nervios enjarjan en el muro mediante una estructura cilíndrica de aspecto columnario, al igual que sucede en la capilla mayor de la parroquia de Santa María de la Oliva de Lebrija, la Sacristía de los Cálices de la catedral de Sevilla y la parroquia de Santa María de Arcos de la Frontera (Fig. 9), obras de cronología similar a las que nos ocupan en las que intervienen maestros lusos y que a su vez son un trasunto de obras
Hay que señalar que Sancho de Sopranis ${ }^{59}$ relaciona el Claustrillo de la Cartuja de Santa María de la Defensión con el claustro procesional de la catedral de Santiago de Compostela, trazado por Juan de Álava en 1510, si bien las obras no comenzaron hasta 1521 y concluyeron en 1527, siempre bajo la supervisión del maestro ${ }^{60}$.

En realidad el aspecto general de ambos claustros es similar, si bien no puede hablarse de plagio, como hace de manera abierta Sancho. Ni los estribos son iguales, ni la crestería tampoco, ni en el claustro compostelano hay columnas en las esquinas. Se podría decir que ambas obras siguen la tónica general de la arquitectura hispánica de la época,

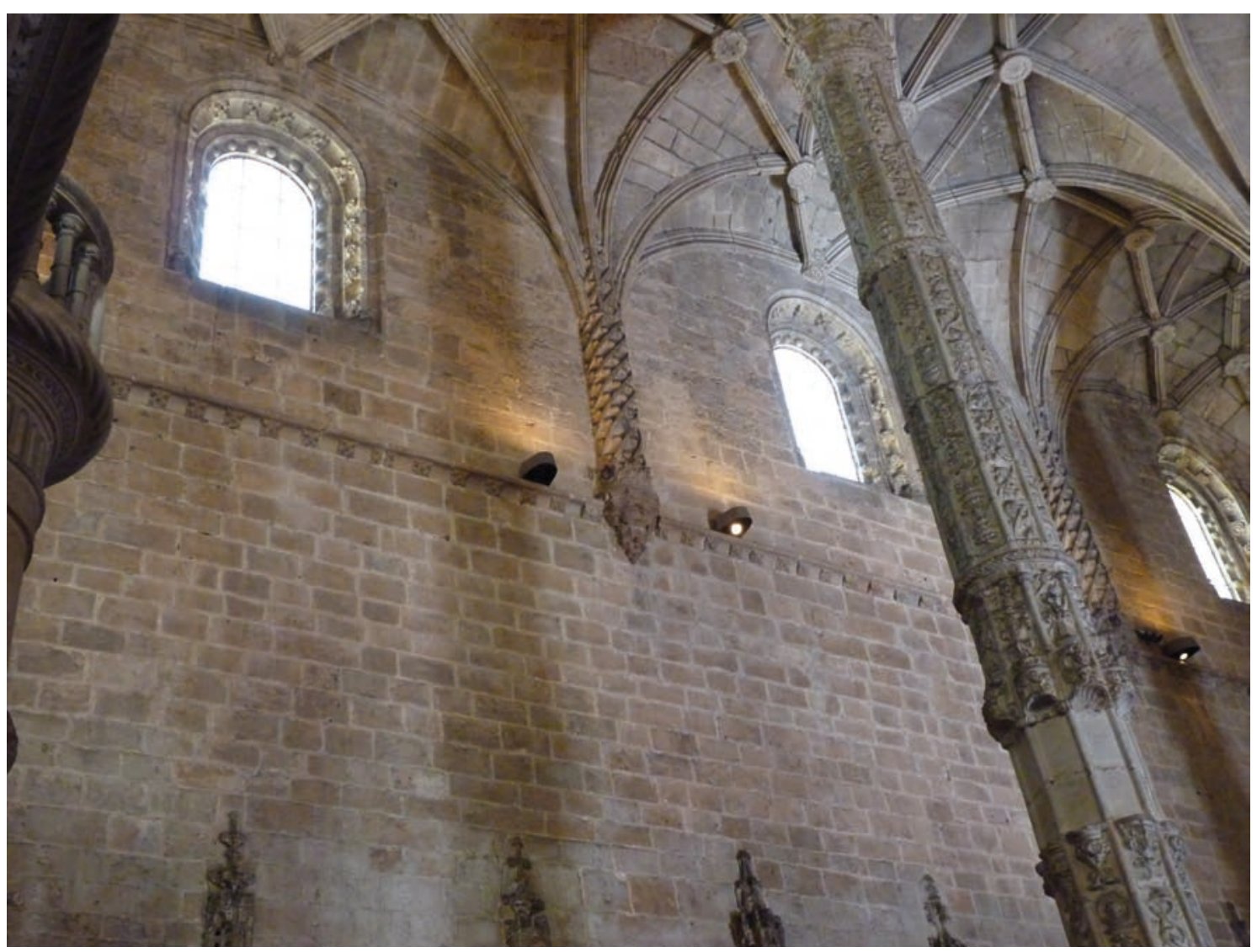

- Fig. 10. Monasterio de los Jerónimos, Lisboa. Detalle de decoración tardogótica lusa. Foto de los autores.

tan significativas del último periodo del gótico del país vecino como la capilla mayor de la catedral de Braga, levantada por Juan del Castillo o la iglesia del monasterio de jerónimos de Belem de Lisboa (Fig. 10).
${ }^{59} \mathrm{H}$. SANCHO DE SOPRANIS, "La arquitectura jerezana del siglo XVI", Archivo Hispalense, 123, 1964, pp. 44 y siguientes.

60 A. CASTRO SANTAMARÍA, Juan de Álava, Salamanca, 2002, p. 33. 
pero poco más. Ni siquiera se puede hablar de una misma traza para ambas obras, pues no tenemos constancia de que Juan de Álava visitase jamás Jerez, estando documentada tan sólo una estancia en Sevilla en 1513, cuando vino junto a Juan Gil de Hontañón para dar informes sobre el hundimiento del cimborrio, acaecido dos años antes. Además, la relación entre Álava y Riaño no parece que fuese demasiado buena, pues incluso este llego a arrebatarle a aquel la dirección de obras de la colegiata de Valladolid y dio informes negativos sobre su proyecto para la catedral de Salamanca.

\section{CONCLUSIONES}

El proceso constructivo de la iglesia y el claustrillo de la jerezana cartuja de Santa María de la Defensión pone de manifiesto el complejo sistema de dirección de obras en la Baja Andalucía durante las primeras décadas del XVI. Además, el caso que nos ocupa es un tanto especial, ya que se trata de un cenobio de grandes dimensiones y con muy buenos recursos económicos, lo que le permitió lanzarse a una frenética actividad edilicia en ese momento. Pese a la austeridad de los monjes cartujos, su afán por ensalzar el culto divino les hizo buscar a los mejores artífices para embellecer su casa. Por eso no debe extrañarnos que Juan Gil de Hontañón diese trazas para los estribos de la iglesia, ni que Riaño dirigiese las obras durante un periodo. Pero los cartujos, por más dinero que tuviesen, no podían retener a maestros de prestigio que eran reclamados de diferentes puntos de Castilla, como es el caso de Diego de Riaño en Valladolid. Es ahí donde entra la figura de Andrés Núñez del Río, ese maestro local, buen conocedor de las técnicas constructivas tradicionales y hombre conocido por los arquitectos de primera fila, ya que su actividad como agente de la Catedral de Sevilla en la compra de piedra, le hizo estar en contacto con sus maestros mayores, quienes confiaban en él hasta el punto de delegar en su persona algo tan importante como el suministro de material. Así, se puede hablar de una maestría mayor en la cartuja de la
Defensión de Andrés Núñez del Río, aunque esta maestría fuese auxiliar o condicionada por una superior ostentada por Riaño.

\section{BIBLIOGRAFÍA}

ALONSO RUIZ, B., “Diego de Riaño y los maestros de la Colegiata de Valladolid", De Arte, 3, 2004, pp. 39-53.

ÁLVAREZ LUNA, M. A., AROCA VICENTI, F., GUERRERO VEGA, J. M. y ROMERO BEJARANO, M., "La iglesia de San Ildefonso", en J. JIMÉNEZ LÓPEZ DE EGUILETA (ed.), La Parroquia de San Mateo de Jerez de la Frontera. Historia, arte y arquitectura, Murcia, 2017 (en prensa).

CAGIGAS ABERASTURI, A.I., Los maestros canteros de Trasmiera. Santander, Tesis Doctoral defendida en la Universidad de Cantabria, Santander, 2016.

CAMÓN AZNAR, J., La Arquitectura y la Orfebrería Española del siglo XVI, vol. XVII, Madrid, 1959.

CARTUJO DE LA DEFENSIÓN, "El Claustrillo de la Cartuja de la Defensión", Temas de Estética y Arte, IX, 1995, pp. 173200.

FALCÓN MÁRQUEZ, T., La catedral de Sevilla. Estudio Arquitectónico, Sevilla, 1980.

GESTOSO PÉREZ, J., Sevilla Monumental y Artística. Historia y Descripción de todos los Edificios Notables, Religiosos y Civiles, que existen actualmente en esta ciudad y noticias de las preciosidades artísticas y arqueológicas que en ello se conservan, T. II, Sevilla, 1890.

HERNÁNDEZ DÍAZ, J., Documentos para la Historia del Arte en Andalucía, Sevilla, 1933.

MARTÍN GONZÁLEZ, J. J. y URREA FERNÁNDEZ, J., Catálogo Monumental de Valladolid. Monumentos religiosos de la ciudad de Valladolid (Catedral, parroquia, cofradías y santuarios), Valladolid, 1985.

MAYO ESCUDERO, J. (ed.), Protocolo primitivo y de fundación de la Cartuja Santa María 
de la Defensión. Jerez de la Frontera (Cádiz), Salzburgo, 2001.

MINGORANCE RUIZ, J.A., "La presencia flamenca en la Cartuja de Santa María de la Defensión de Jerez de la Frontera", Atrio, 18, 2002, pp. 137-150.

MORALES MARTÍNEZ, A.J., La obra renacentista del Ayuntamiento de Sevilla, Sevilla, 1981.

"Diego de Riaño en Lisboa", Archivo Español de Arte, 264, 1993, pp. 404-408.

PINTO PUERTO, F., Las esferas pétreas. Análisis de las soluciones del arte de la montea en la provincia de Cádiz durante el siglo XVI, Tesis doctoral defendida en la Universidad de Sevilla, Sevilla, 1998.

RODRÍGUEZ ESTÉVEZ, J.C., Los canteros de la Catedral de Sevilla. Del Gótico al Renacimiento, Sevilla, 1998.

Cantera y Obra: las canteras de la Sierra de San Cristóbal y la Catedral de Sevilla, El Puerto de Santa María, 1998.

“El Gótico Catedralicio. La Influencia de la Catedral en el Arzobispado de Sevilla", en Simposium Internacional Sobre la Catedral de Sevilla en el Contexto del Gótico Final, Sevilla, 2007, pp. 175-255.

"El maestro Alonso Rodríguez", en B. ALONSO RUIZ (ed.), Los últimos arquitectos del gótico, Madrid, 2010, pp. 271-360.

ROMERO BEJARANO, M., "El maestro Arnao de Vergara, autor de las primitivas vidrieras de la iglesia de la cartuja de Santa María de la Defensión de Jerez de la Frontera", en I. COLOMA MARTín y
J. A. SÁNCHEZ LÓPEZ (eds.), Actas del XIV Congreso Nacional de Historia del Arte, T. II, Málaga, 2003, pp. 451-458.

Maestros y obras de ascendencia portuguesa en el tardogótico de la Baja Andalucía, Tesis doctoral defendida en la Universidad de Sevilla, Sevilla, 2014.

ROMERO MEDINA, R., Arquitectura medieval en El Puerto de Santa María. Del Islam a los inicios del Renacimiento, Tesis doctoral defendida en la Universidad de Cádiz, Cádiz, 2009.

ROMERO MEDINA, R. y ROMERO BEJARANO, M., "Un lugar llamado Jerez. El maestro Alonso Rodríguez y sus vínculos familiares y profesionales en el contexto de la arquitectura del tardogótico en Jerez de la Frontera", en La Catedral después de Carlín, Sevilla, 2010, pp. 173-288.

“Las marcas de cantería del puente de Cartuja de Jerez de la Frontera: Análisis Gliptográfico", en Actes du XVIIe Colloque International de Glyptographie a Cracovie, Braine-le-Château, 2011, pp. 319-332.

“Burgos, Jerez y Salamanca. Juan Gil de Hontañón y su obra en la parroquia de Jerez de la Frontera. Repercusiones en la catedral nueva de Salamanca", en M. CASAS HERNÁNDEZ (coord.), La catedral de Salamanca: de fortis a magna, Salamanca, 2014, pp. 2033-2046.

SANCHO DE SOPRANIS, H., "La arquitectura jerezana del siglo XVI", Archivo Hispalense, 123, 1964, pp. 9-76.

SOJO Y LOMBA, F., Los maestros canteros de Trasmiera, Madrid, 1935. 